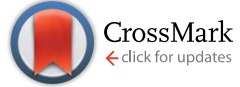

Cite this: RSC Adv., 2015, 5, 69861

\title{
Molecular architecture control in synthesis of spherical Ln-containing nanoparticlestt
}

\author{
Wuyuan Zhang, ${ }^{a}$ Jonathan Martinelli, ${ }^{a}$ Florian Mayer, ${ }^{a}$ Célia S. Bonnet, ${ }^{b}$ \\ Frédéric Szeremeta ${ }^{b}$ and Kristina Djanashvili ${ }^{\star a}$
}

Among the procedures to prepare lanthanide-containing nanoparticles a gap exists in the range between 5 and $40 \mathrm{~nm}$. The miniemulsion technique presented here is intended to fill this discontinuity and offers a facile method that can be applied for the preparation of nanoparticles for various applications, e.g. medical imaging, optics and catalysis. We demonstrate that formation of nanodroplets under emulsion conditions is the key step in the size control of the nanoparticles. The type of surfactant and the nature of the dispersed and continuous phases strongly influence the interfacial activity and, consequently, the size of the final solid particles that result from the subsequent thermal decomposition. Moreover, the choice of the surfactant determines the final elemental composition of the particles, leading to either lanthanide oxides or oxysulfates when using Brijß 35 or sodium dodecyl sulfate, respectively. Nanoparticles of holmium and gadolinium were prepared and their applicability as magnetic resonance imaging contrast agents is shown.

Received 19th May 2015

Accepted 10th August 2015

DOI: $10.1039 / \mathrm{c} 5 \mathrm{ra0} 9374 \mathrm{k}$

www.rsc.org/advances
$T_{1^{-}}$or $T_{2}$-weighted imaging. Since the efficacy of positive $\left(T_{1}\right)$ nanoparticulate CAs depends on the interaction of water molecules with paramagnetic ions at the surface of NPs, a high surface-to-volume ratio is required and thus NPs with a diameter smaller than $10 \mathrm{~nm}$ are preferred. On the other hand, negative $\left(T_{2}\right)$ contrast depends on magnetic susceptibility and the magnitude of magnetic moment, which are in direct relation with the number of paramagnetic ions per particle and hence the size of the applied NP.

A large number of publications reports on Ln-based NPs such as oxides, ${ }^{14,15}$ carbonates, ${ }^{16}$ oxysulfides, ${ }^{17}$ polysiloxane networks,${ }^{18}$ hybrids, ${ }^{19}$ zeolites, and porous silica supporters. ${ }^{6}$ The size of these particles varies widely in the range of 1-200 nm depending on the preparation methodologies applied. The polyol method is particularly useful to prepare ultrasmall Gdoxide NPs $(1-3 \mathrm{~nm}) .^{20}$ However, for larger particles this procedure is time-consuming due to slow nucleation and the need for repetition of seed growth, and poorly reproducible as there is no control over the yield and uniformity of the resultant NPs. The polyol method has also raised concerns about inhibitory effects on neutrophil oxidative burst that might be caused by the presence of diethylene glycol on the surface of particles prepared in such solvent. ${ }^{21}$ We have previously reported that Ln carbonate NPs (turning into oxides upon calcination) can be readily prepared via controlled microwave-assisted seed growth. ${ }^{16}$ The smallest size achievable with reasonable yield and good homogeneity by this method is $40 \mathrm{~nm}$, as demonstrated by dynamic light scattering. Finally, the solvothermal method is dominating in the synthesis of upconversion NPs with highly controlled size and morphological uniformity. The resulting

\footnotetext{
${ }^{a}$ Department of Biotechnology, Delft University of Technology, Julianalaan 136, 2628 BL, Delft, The Netherlands. E-mail: k.djanashvili@tudelft.nl

${ }^{b}$ Centre de Biophysique Moléculaire, UPR4301, CNRS, Université d'Orléans, Rue Charles Sadron, 45071 Orléans Cedex 2, France

$\dagger$ This paper is dedicated to Professor Imre Tóth from the University of Debrecen, Hungary on the occasion of his 65th birthday.

\$ Electronic supplementary information (ESI) available: XRD, EDS, FT-IR, TGA, and TEM measurements of the dried Ho- and Gd-containing droplets and corresponding nanoparticles. See DOI: 10.1039/c5ra09374k
} 
particles have promising applicability in optical imaging, but their usefulness with respect to MRI is limited..$^{22}$ Recently, Eu-doped $\mathrm{Gd}_{2} \mathrm{O}_{3}$ particles in a $5-200 \mathrm{~nm}$ range for multimodal/ sequential CAs prepared by chemical vapor synthesis at high temperature have been reported. ${ }^{23}$ Alternatively, a laser ablation method performed by focusing the laser beam onto a Gd target has been described, ${ }^{24}$ resulting in spherical $\mathrm{Gd}_{2} \mathrm{O}_{3}$ particles with an average diameter of $7 \mathrm{~nm}$.

The miniemulsion (or nanoemulsion) technique, widely applied in polymer chemistry, ${ }^{25,26}$ is however uncommon for the preparation of inorganic NPs. Considering the great interest towards NPs with defined size, we describe herein a novel miniemulsion method for the facile size-controlled preparation of spherical Ln-based NPs in the otherwise not readily accessible range of 5-40 nm. A miniemulsion consists of dispersed nanosized droplets formed from two phases of different polarity upon exposure to high power ultrasound. The resulting nanodroplets usually have a narrow size distribution and can be well stabilized in emulsion by an appropriate surfactant. The formation of the droplets highly depends on tunable factors such as composition, phase or surfactant, ${ }^{25}$ and the miniemulsion technique can be extended to the generation of composite materials, in which different metals as well as surface coatings can be incorporated..$^{27-29}$

The method reported herein involves two steps: an easy and efficient preparation of miniemulsions consisting of Ln nanodroplets, and a subsequent thermal decomposition to obtain Ln-containing solid particles. It is noteworthy that the nature of the product obtained through thermal decomposition is highly dependent on the surfactant in the continuous phase: for example $\mathrm{Ln}_{2} \mathrm{O}_{3}$ is obtained using Brij ${ }^{\circledR} 35$, while $\mathrm{Ln}_{2} \mathrm{O}_{2} \mathrm{SO}_{4}$ is produced in the presence of sodium dodecyl sulfate (SDS). This simple miniemulsion method opens new and interesting alternatives to prepare NPs for a variety of applications, including imaging and therapy.

\section{Experimental section}

\section{Materials and methods}

All chemicals were used as supplied from commercial sources: analytical grade solvents, sodium dodecyl sulfate, octadecane (Sigma-Aldrich), polyethylene glycol dodecyl ether (Brij® 35, $M_{\mathrm{n}}$ $\sim 1198$ ), acetylacetone (acac) (Fluka). " $\mathrm{H}_{2} \mathrm{O}$ " refers to high purity water with conductivity of $0.04 \mu \mathrm{S} \mathrm{cm}^{-1}$, obtained from a Milli-Q purification system. Lanthanide chlorides $\left(\mathrm{LnCl}_{3} \cdot 6 \mathrm{H}_{2} \mathrm{O}\right.$, Strem Chemicals) were dissolved in $10 \mathrm{ml}$ water, the obtained solutions were filtered over a $200 \mu \mathrm{m}$ nylon syringe filter and evaporated to dryness under high vacuum before use. $\operatorname{Ln}(\mathrm{acac})_{3}$ were synthesized according to published procedures: ${ }^{30}$ typically, acetylacetone $(0.220 \mathrm{~mol})$ was dissolved in $\mathrm{H}_{2} \mathrm{O}(135 \mathrm{ml})$ and the $\mathrm{pH}$ of this solution was adjusted to 8.5 by portion-wise addition of $25 \%$ ammonium hydroxide; $\mathrm{LnCl}_{3}(10 \mathrm{mmol} ; \mathrm{Ln}=\mathrm{Gd}$, Ho) was dissolved in $\mathrm{H}_{2} \mathrm{O}(5 \mathrm{ml})$ and slowly added to the abovementioned solution under stirring. The mixture was stirred overnight and the pink $\left(\mathrm{Ho}(\mathrm{acac})_{3}\right)$ or white $\left(\mathrm{Gd}(\mathrm{acac})_{3}\right)$ crystals were filtered, washed three times with water and air-dried.

\section{Preparation of Ln-containing nanodroplets by a miniemulsion method}

In a typical procedure to prepare the miniemulsion, the dispersed hydrophobic phase was obtained by mixing $\operatorname{Ln}(\mathrm{acac})_{3}$ $(50 \mathrm{mg})$ in $\mathrm{CHCl}_{3}$ or dichloromethane (DCM) $(2.5 \mathrm{ml})$. This suspension was then added dropwise to a continuous phase consisting of SDS or Brij® 35 dissolved in $\mathrm{H}_{2} \mathrm{O}(8 \mathrm{ml})$. The mixture was vigorously stirred at room temperature for $1 \mathrm{~h}$ (preemulsion) and then ultrasonicated (Qsonica Sonicator, $500 \mathrm{~W}$, 1/2 inch tip, $80 \%$ amplitude, time interval $0.5 \mathrm{~s}$ ) for 5 min under ice cooling, yielding milky miniemulsions (pink for Ho and white for Gd). The hydrophobic solvents were removed by careful rotary evaporation at $30^{\circ} \mathrm{C}$ to avoid aggregation, until a turbid dispersion appeared. These dispersions were used to measure the hydrodynamic radius of the nanodroplets, and they were then freeze-dried yielding Ln-containing powders.

\section{Phase transformation}

Thermal decomposition of the previously obtained powders was performed by calcination at $800^{\circ} \mathrm{C}$ under air atmosphere for $1 \mathrm{~h}$ applying a heating rate of $2.5^{\circ} \mathrm{C} \mathrm{min}^{-1}$. The average yield of this procedure was $82 \%$ with respect to $\operatorname{Ln}(\mathrm{acac})_{3}$.

\section{Characterization}

The size of the nanodroplets in the miniemulsion was measured by dynamic light scattering (DLS). The experiments were carried out by using a Malvern Zetasizer NanoZS operating in a particle size range from $0.6 \mathrm{~nm}$ to $6 \mu \mathrm{m}$ and equipped by a $\mathrm{He}-\mathrm{Ne}$ laser with $\lambda=633 \mathrm{~nm}$. The measurements were performed at $25{ }^{\circ} \mathrm{C}$, and the average diameter was based on three individual measurements, 20 scans for each measurement. To evaluate the process of conversion of the freeze-dried Ln-containing nanodroplets into solid particles, thermogravimetric analysis (TGA) was conducted by using a Perkin-Elmer Thermogravimetric Analyzer TGA7 equipped with a Thermal Analysis Controller TAC 7/DX, from 25 to $900{ }^{\circ} \mathrm{C}\left(10^{\circ} \mathrm{C} \mathrm{min}^{-1}\right)$ under air atmosphere. X-ray diffractometry (XRD) measurements were performed on a Bruker D8 Advance X-ray diffractometer using Co K $\alpha$ radiation ( $1.789 \AA)$ at $35 \mathrm{kV}$ and $40 \mathrm{~mA}$. The data were collected from $5^{\circ}$ to $80^{\circ} 2 \theta$ with a step size of $0.020^{\circ} 2 \theta$ and a counting time of $0.5 \mathrm{~s}$ per step. Lattice constants were calculated and corrected using MDI JADE software. Transmission electron microscopy (TEM) analyses were performed on a JOEL JEM-2100 transmission electron microscope. Samples of nanoparticles from dilute aqueous dispersions were evaporated over a 400-mesh copper measurement grid. The instrument operated at an accelerating voltage of $200 \mathrm{kV}$ for the acquisition of section images. The surface composition of formed NPs was characterized by Infrared (IR) spectroscopy performed on a Perkin-Elmer Spectrum One FT-IR spectrometer using $\mathrm{KBr}$ tablet. The chemical composition of NPs was analyzed by energy dispersive X-ray spectroscopy (EDS) on a JEOL-JMS 6010 scanning electron microscope with an acceleration voltage of $20 \mathrm{kV}$. The longitudinal $\left(T_{1}\right)$ and transversal $\left(T_{2}\right)$ water proton relaxation times were measured on a Varian-INOVA 300 NMR 
spectrometer applying inversion recovery and CPMG sequences, respectively. For the latter sequence the half interval time $\left(\tau_{\mathrm{cp}}\right)$ between the successive $180^{\circ}$ pulses was fixed at $1.0 \mathrm{~ms}$. The samples for these measurements were prepared by suspending defined amounts of particles in $0.5 \%$ xanthan gum solution. The same equipment was exploited to determine the concentrations of $\mathrm{Ln}^{3+}$ ( $\mathrm{Ln}=$ Ho and $\mathrm{Gd}$ ) ions in the aqueous solutions via bulk magnetic susceptibility (BMS) method. ${ }^{31}$ MRI experiments were conducted on a PharmaScan $7 \mathrm{~T}$ horizontal magnet (B-C 70/16 US, Bruker BioSpin, Wissembourg, France) equipped with B-GA09 gradient system $\left(120 \mathrm{mT} \mathrm{m}^{-1}\right.$ maximal strength and $90 \mathrm{~mm}$ inner diameter) and Paravision 4.0 software (Bruker BioSpin). $T_{1}$-weighted and $T_{2}$-weighted $\mathrm{MR}$ images were acquired with spin-echo sequence (RARE sequence with one echo to get a small echo time (TE) and to make the effective-TE equal to TE) at $25{ }^{\circ} \mathrm{C}$. $T_{1}$-weighted images were acquired with $10.6 \mathrm{~ms} \mathrm{TE}$ and $250 \mathrm{~ms}$ TR (repetition time) and $200 \times 200 \mu \mathrm{m}^{2}$ resolution with a matrix $128 \times 128 \mathrm{in} 32 \mathrm{~s}$. $T_{2}$-weighted images were acquired with $90 \mathrm{~ms}$ TE and $3000 \mathrm{~ms}$ TR and $400 \times 400$ $\mu \mathrm{m}^{2}$ resolution with a matrix $64 \times 64$ in $3 \mathrm{~min}$. All images have $2.0 \mathrm{~mm}$ thickness.

\section{Results and discussion}

\section{Formation of the nanodroplets}

In order to obtain a miniemulsion containing homogeneous and stable nanodroplets, a hydrophobic dispersed phase and a hydrophilic continuous phase need to be mixed and sonicated. In general, once homogeneously distributed nanodroplets are obtained, no decomposition or aggregation takes place and the nanodroplets can be converted into a solid material by removal of the solvents. This strategy was successfully exploited for the synthesis of lanthanide-containing NPs (Scheme 1).

Homogeneous nanodroplets in miniemulsion were prepared by powerful sonication of a mixture of $\operatorname{Ln}(\mathrm{acac})_{3}$ in the dispersed phase and surfactant in the continuous phase. The conditions of sonication in terms of mechanical energy and duration were chosen to allow the nanodroplets in emulsion to reach a steady state. ${ }^{30}$

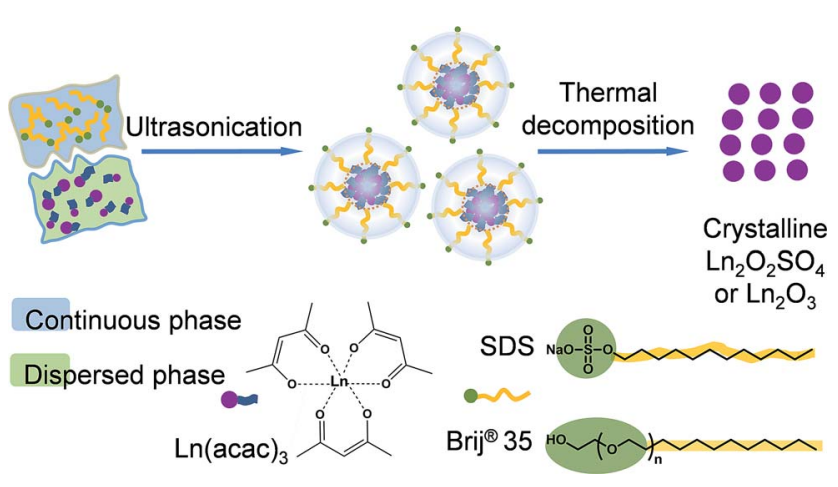

Scheme 1 Two-step preparation of Ln-NPs. Small and homogeneous nanodroplets in miniemulsion were first achieved by powerful sonication followed by evaporation of the hydrophobic solvent; freezedrying and subsequent calcination led to the aimed systems.
The presence of a surfactant facilitates the nucleation by forming a region of hydrophobic tails where nanosized chloroform or dichloromethane cores containing $\operatorname{Ln}(\text { acac })_{3}$ are trapped and act as nanoreactors; the hydrophilic moieties extend into a polar continuous phase of water. Such configuration provides discrete particle formation. The resulting nanodroplets were then isolated and thermally decomposed into solid nanoparticles.

Different synthetic conditions, such as combinations and amounts of solvents and surfactants, were investigated (Table 1). The various products obtained were preliminary characterized via DLS size measurements. At first, preparations were carried out with $\mathrm{Ho}(\mathrm{acac})_{3}$ in chloroform as dispersed phase, while SDS was used as surfactant in the aqueous phase. It is a common strategy in miniemulsion techniques to add a hydrophobic co-stabilizing agent to stabilize the droplets against Ostwald ripening. ${ }^{32}$ Here, we selected octadecane to adjust the osmotic pressure of the miniemulsion. It appeared that the presence of octadecane in the dispersed phase had a positive effect on reducing the size of the Ho-containing droplets, but decreasing its concentration led to higher polydispersity index (PDI) values (Table 1, entries 1-3). TEM images of the particles obtained after thermal decomposition of these droplets showed that the presence of octadecane leads to less homogenous solid particles (Fig. S1 $\$$ ). Therefore, a hydrophobic agent was omitted in the next preparations in order to achieve a better homogeneity of the resultant solid particles.

Although it has been demonstrated that in general the concentration of surfactant plays a crucial role in controlling the size of the droplets, ${ }^{33}$ this effect was observed only to a limited extent in the present case: varying the concentration of SDS in the continuous phase from 10 to $30 \mathrm{mM}$ (Table 1, entries 3 and 4) did not change the droplet size significantly (as measured by DLS, 45 vs. $51 \mathrm{~nm}$ ). Furthermore, increasing the SDS concentration over $30 \mathrm{mM}$ resulted in unstable nanodroplets precipitating within 3 days.

The diffusion of the dispersed phase through the water phase has been shown to limit the growth of nanodroplets. ${ }^{25}$ With this in mind, we investigated the use of more polar DCM as the solvent of the dispersed phase. When keeping the other conditions unmodified (Table 1, entries 3 and 5) the diameter of the droplets in the miniemulsion was only $26 \mathrm{~nm}$ as compared to $45 \mathrm{~nm}$ in $\mathrm{CHCl}_{3}$. This can be explained in terms of a different interface activity, where the interfacial tension is $32.80 \mathrm{mN} \mathrm{m}^{-1}$ for $\mathrm{H}_{2} \mathrm{O} / \mathrm{CHCl}_{3}$ and $28.31 \mathrm{mN} \mathrm{m}^{-1}$ for $\mathrm{H}_{2} \mathrm{O} / \mathrm{DCM} .^{34}$ Thus, a relatively minor change in the polarity of the dispersed phase has a strong impact on the formation of the droplets in the miniemulsion. To further investigate this effect, $12.5 \mathrm{wt} \%$ of ethanol was added to the continuous phase to improve the diffusion at the interface between $\mathrm{H}_{2} \mathrm{O}$ and DCM: ${ }^{35}$ this led to an increase in the size of the nanodroplets from 26 to $37 \mathrm{~nm}$ (Table 1, entries 5 and 6), in accordance with the improved solubility of $\operatorname{Ln}(\mathrm{acac})_{3}$ and the higher miscibility of DCM towards the continuous phase. Doubling the concentration of SDS for the $\mathrm{H}_{2} \mathrm{O}+\mathrm{EtOH} / \mathrm{DCM}$ resulted in notably bigger nanodroplets (from 37 to $57 \mathrm{~nm}$; Table 1, entries 6 and 7). It was also noticed that with anionic SDS as surfactant, the PDIs of the 
Table 1 Experimental data for the preparation of Ln-containing nanodroplets and NPs under different conditions

\begin{tabular}{|c|c|c|c|c|c|c|c|c|c|}
\hline Entry & Metal $^{a}$ & $\begin{array}{l}\text { Dispersed } \\
\text { phase }^{b}\end{array}$ & $\begin{array}{l}\text { Octadecane } \\
(\mathrm{mg})\end{array}$ & $\begin{array}{l}\text { Continuous } \\
\text { phase }\end{array}$ & $\begin{array}{l}\text { Surfactant } \\
(\mathrm{mM})\end{array}$ & $\begin{array}{l}\text { DLS sized } \\
(\mathrm{nm})\end{array}$ & PDI & $\begin{array}{l}\text { Product after } \\
\text { calcination }^{e}\end{array}$ & $\begin{array}{l}\text { TEM size } \\
(\mathrm{nm})\end{array}$ \\
\hline 1 & Но & $\mathrm{CHCl}_{3}$ & 30 & $\mathrm{H}_{2} \mathrm{O}$ & SDS (10) & $37 \pm 6$ & 0.25 & $\mathrm{Ho}_{2} \mathrm{O}_{2} \mathrm{SO}_{4}$ & $15 \pm 3.1$ \\
\hline 3 & Ho & $\mathrm{CHCl}_{3}$ & 0 & $\mathrm{H}_{2} \mathrm{O}$ & SDS (10) & $45 \pm 4$ & 0.37 & $\mathrm{Ho}_{2} \mathrm{O}_{2} \mathrm{SO}_{4}$ & $24 \pm 5.7$ \\
\hline 4 & Ho & $\mathrm{CHCl}_{3}$ & 0 & $\mathrm{H}_{2} \mathrm{O}$ & SDS (30) & $51 \pm 7$ & 0.44 & $\mathrm{Ho}_{2} \mathrm{O}_{2} \mathrm{SO}_{4}$ & $-^{f}$ \\
\hline 5 & Ho & DCM & 0 & $\mathrm{H}_{2} \mathrm{O}$ & SDS (10) & $26 \pm 3$ & 0.39 & $\mathrm{Ho}_{2} \mathrm{O}_{2} \mathrm{SO}_{4}$ & $8 \pm 1.8$ \\
\hline 8 & Ho & DCM & 0 & $\mathrm{H}_{2} \mathrm{O}$ & Brij® 35 (5.2) & $109 \pm 9$ & 0.087 & $\mathrm{Ho}_{2} \mathrm{O}_{3}$ & $12 \pm 2.0$ \\
\hline 9 & $\mathrm{Gd}$ & DCM & 0 & $\mathrm{H}_{2} \mathrm{O}$ & SDS (10) & $33 \pm 7$ & 0.40 & $\mathrm{Gd}_{2} \mathrm{O}_{2} \mathrm{SO}_{4}$ & ${ }^{f}$ \\
\hline 10 & Gd & DCM & 0 & $\mathrm{H}_{2} \mathrm{O}$ & Brij ${ }^{\circledR} 35$ (5.2) & $98 \pm 11$ & 0.10 & $\mathrm{Gd}_{2} \mathrm{O}_{3}$ & $7 \pm 2.1$ \\
\hline
\end{tabular}

${ }^{a} 50 \mathrm{mg}$ of $\mathrm{Ln}(\mathrm{acac})_{3}$ for each batch. ${ }^{b} 2.5 \mathrm{ml}$ for each batch. ${ }^{c}$ With respect to the continuous phase. ${ }^{d}$ Average diameter. ${ }^{e}$ As determined by XRD. ${ }^{f}$ Not measured.

obtained nanodroplets were relatively high (generally between 0.3 and 0.4 ). This may be explained by the effect of collisions between nanodroplets: the smaller the droplets, the shorter the distance and the higher their number, thus the collision rate increases; eventually, this leads to destabilization and a broader PDI. ${ }^{36}$ However, when SDS was replaced with Brij ${ }^{\circledR} 35$, a purely organic and non-ionic surfactant, the PDI dropped dramatically (e.g. 0.09 vs. 0.39; Table 1, entries 5 and 8). At the same time the size of the nanodroplets increased significantly (109 vs. $26 \mathrm{~nm})$. The latter phenomenon is the consequence of the good affinity between water and the long hydrophilic polyethylene glycol chain of Brij® 35 .

Once the factors playing a role in the preparation of Honanodroplets were assessed, their applicability and reproducibility were checked by preparing analogous Gd-based systems. With $\mathrm{Gd}(\mathrm{acac})_{3}$ under the same conditions (Table 1, entries 5 and 9) the obtained Gd-nanodroplets had a size of $33 \mathrm{~nm}$, consistent with the value previously measured for the corresponding Ho-based products $(26 \mathrm{~nm})$. Also the replacement of SDS with Brij® 35 as surfactant had similar effects (Table 1, entries 9 and 10); a remarkable increase in size (98vs. $33 \mathrm{~nm})$ and a significant lowering of the PDI (from 0.40 to 0.10 ). These results show that the formation of nanodroplets in a miniemulsion process can be reliably tuned not only by adjusting the polarity of the two phases, but also by playing with the other components in general and the surfactant in particular.

\section{Formation of the nanoparticles}

The second step in the preparation of Ln-NPs consists of the transformation of the nanodroplets from the miniemulsion into solid particles through calcination (Scheme 1). Both the Ho- and Gd-containing nanodroplets were dried and then decomposed under aerobic conditions at $800{ }^{\circ} \mathrm{C}$ for $1 \mathrm{~h}$. The nature of the product after thermal decomposition turned out to depend on the surfactant added during the synthesis. When SDS was used, the calcination yielded oxysulfates $\left(\operatorname{Ln}_{2} \mathrm{O}_{2} \mathrm{SO}_{4}\right)$ nanocrystals, the surfactant being the source of sulfur. The evolution in the crystal structure can be observed by X-ray powder diffraction measurements (Fig. 1): the XRD pattern of the dried Ho-nanodroplets is mainly featureless, indicating a basically amorphous nature (Fig. S2 ); after calcination, $\mathrm{Ho}_{2} \mathrm{O}_{2} \mathrm{SO}_{4}$ is obtained instead in a crystalline form (Fig. 1a, top). All the XRD reflections revealed a crystal structure of $\mathrm{Ho}_{2} \mathrm{O}_{2} \mathrm{SO}_{4}$ with calculated lattice constants $a=4.045 \AA, b=4.185 \AA$ and $c=$ $12.963 \AA$. In addition, a diffraction peak of $\mathrm{Ho}_{2} \mathrm{O}_{3}$ was observed (Fig. 1a), the intensity of which was mainly dependent on the applied $\mathrm{Ho}(\mathrm{acac})_{3}$ : SDS ratio.

The thermal decomposition of Gd-containing nanodroplets showed analogous effects (Fig. 1a, bottom). Noteworthy, it is possible to obtain $\mathrm{Ln}_{2} \mathrm{O}_{2} \mathrm{SO}_{4}$ NPs with higher purity by adjusting the molar ratio of the starting materials, as shown for $\mathrm{Gd}(\mathrm{acac})_{3}$ and SDS during the preparation of the corresponding nanodroplets. The XRD pattern of the obtained crystalline $\mathrm{Gd}_{2} \mathrm{O}_{2} \mathrm{SO}_{4}$ reveals calculated lattice constants $a=4.051 \AA$, $b=4.174 \AA$ and $c=12.973 \AA$.

When non-ionic surfactant Brij® 35 was used in the miniemulsion, the subsequent thermal decomposition yielded crystalline oxide $\left(\mathrm{Ln}_{2} \mathrm{O}_{3}\right)$ nanocrystals (Fig. $\left.1 \mathrm{~b}\right)$. All reflections in the XRD spectra can be indexed to the cubic structure of $\operatorname{Ln}_{2} \mathrm{O}_{3}$ (space group: $I a \overline{3}$ (no. 206)) with calculated lattice constants $a=$ $10.606 \AA$ for $\mathrm{Ho}_{2} \mathrm{O}_{3}$ and $a=10.812 \AA$ for $\mathrm{Gd}_{2} \mathrm{O}_{3}$, in perfect agreement with those reported (JCPDS 44-1268, $a=10.610 \AA$ and JCPDS 65-3181, $a=10.818 \AA$ respectively). The observed red shift of the patterns is attributed to the use of Co $\mathrm{K} \alpha$ radiation $(1.789 \AA)$ instead of usual $\mathrm{Cu}(1.541 \AA)$.

TGA profiles of the thermal decompositions were recorded (Fig. 2). The starting material $\mathrm{Ho}(\mathrm{acac})_{3}$ has a major multistep weight loss in the temperature range $30-550{ }^{\circ} \mathrm{C}$ that includes the dehydration from structurally bound water between 30 and $200{ }^{\circ} \mathrm{C}$ and decomposition of the organic chelate acetylacetonate up to $550{ }^{\circ} \mathrm{C}$; holmium oxide is finally obtained. The thermogravigram between 30 and $850{ }^{\circ} \mathrm{C}$ of a sample of Ho-containing nanodroplets obtained from $\mathrm{Ho}(\mathrm{acac})_{3}$ in the presence of SDS as surfactant shows a dominant loss (45\%) between 170 and $350{ }^{\circ} \mathrm{C}$, that can be attributed to the major decomposition of SDS and acetylacetonate. A total $62 \%$ loss was measured until $760^{\circ} \mathrm{C}$, in agreement with the value calculated when considering the reaction (Scheme 1) with $35 \mathrm{wt} \%$ retained taking $\mathrm{S}$, Ho and $\mathrm{O}$ into account. 

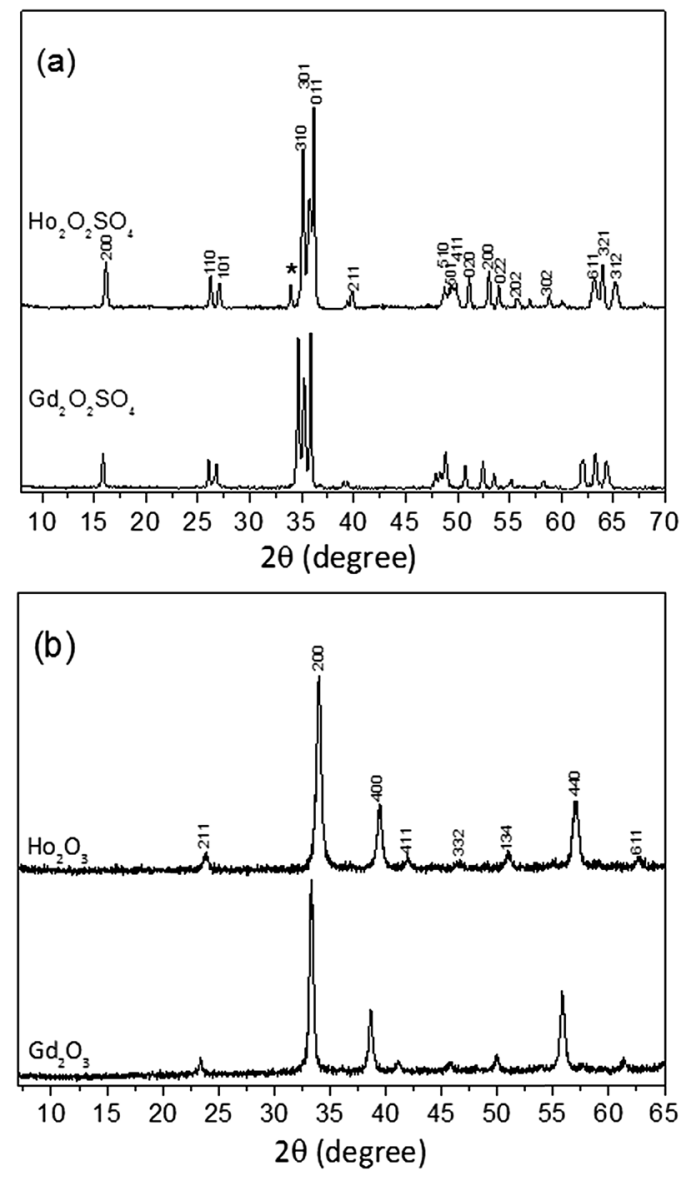

Fig. 1 XRD patterns of the solid Ln-containing NPs obtained by miniemulsion and subsequent open-air thermal decomposition at $800{ }^{\circ} \mathrm{C}$ for $1 \mathrm{~h}$. (a) $\mathrm{Ln}_{2} \mathrm{O}_{2} \mathrm{SO}_{4} \mathrm{NPs}$, SDS was used as surfactant; the peak marked with an asterisk is due to $\mathrm{Ho}_{2} \mathrm{O}_{3}$. (b) $\mathrm{Ln}_{2} \mathrm{O}_{3} \mathrm{NPs}$, Brijß 35 was used as surfactant.

$$
\mathrm{SDS}+\mathrm{Ho}(\mathrm{acac})_{3} \rightarrow \mathrm{Ho}_{2} \mathrm{O}_{2} \mathrm{SO}_{4}
$$

It has been reported that an alternative stacking of $\mathrm{La}_{2} \mathrm{O}_{2}{ }^{2+}$ and $\mathrm{SO}_{4}{ }^{2-}$ layers takes place under treatment at high temperature of hydrous nitrates $\left(\mathrm{Ln}\left(\mathrm{NO}_{3}\right)_{3} \cdot n \mathrm{H}_{2} \mathrm{O}\right)$ intercalated with dodecyl sulfate ions. ${ }^{37,38}$ The gradual decomposition observed in the range $300-700{ }^{\circ} \mathrm{C}$ can thus be ascribed to the stacking mechanism leading to the formation of $\mathrm{Ln}_{2} \mathrm{O}_{2} \mathrm{SO}_{4}$. Such gradual process proceeds until $760{ }^{\circ} \mathrm{C}$ to yield Ln-oxysulfates, in agreement with the XRD evolution (Fig. S3 ). The formation of $\mathrm{Gd}_{2} \mathrm{O}_{2} \mathrm{SO}_{4}$ follows a totally analogous pathway (Fig. 2b).

Different TGA profiles were recorded for dried nanodroplets obtained in the presence of Brijß 35 as surfactant (Fig. 2). The dominant weight loss $(\sim 78 \%)$ between 200 and $500{ }^{\circ} \mathrm{C}$ corresponds to the decomposition of organic Brij ${ }^{\circledR} 35$ and acetylacetonate. Above $500{ }^{\circ} \mathrm{C}$, the thermogravigram reaches a plateau, indicating that $\mathrm{Ho}_{2} \mathrm{O}_{3}$ or $\mathrm{Gd}_{2} \mathrm{O}_{3}$ NPs are obtained.

The surface chemical structure of the obtained various NPs was characterized by Fourier transform infrared spectroscopy (Fig. S4 $\$$. The main starting material $\operatorname{Ln}(\mathrm{acac})_{3}(\mathrm{Ln}=\mathrm{Ho}$ or $\mathrm{Gd})$
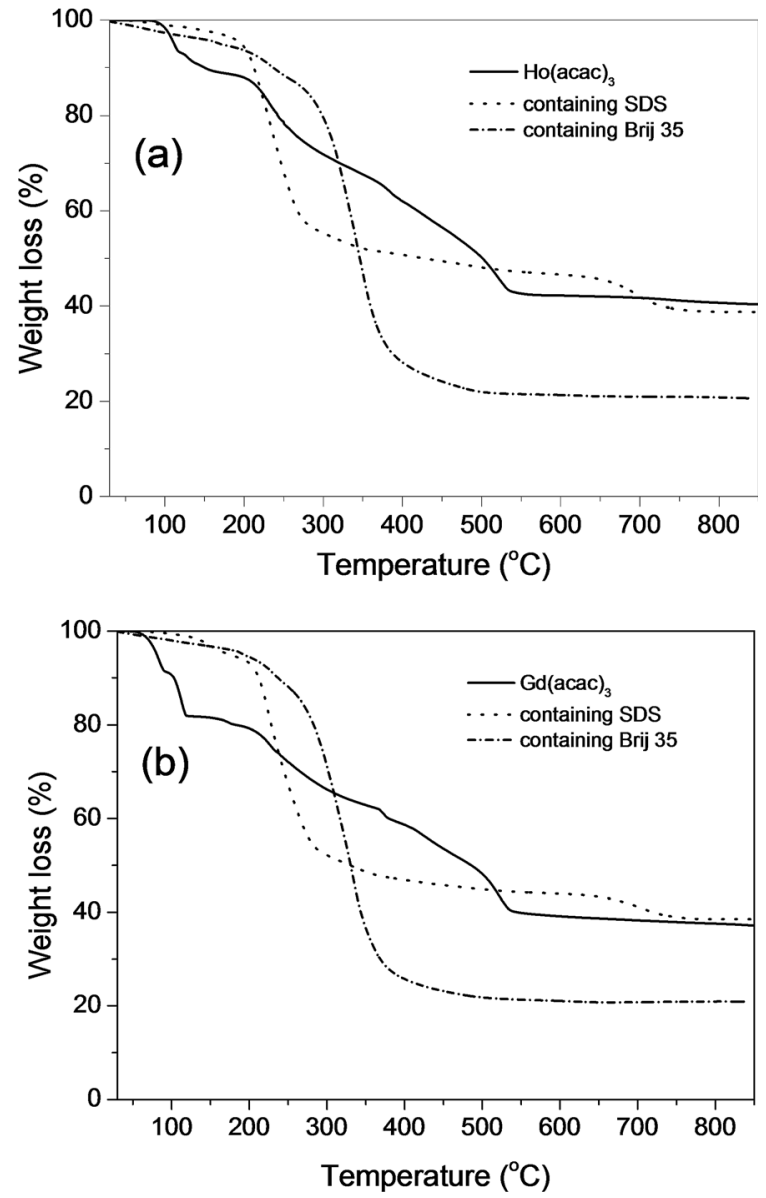

Fig. 2 TGA profiles of $\operatorname{Ln}(\mathrm{acac})_{3}$ and the corresponding Ln-containing nanodroplets prepared by using SDS or Brij® 35 as surfactants. $L n=$ Ho (a) or Gd (b).

shows the characteristic bands of enolized $\beta$-diketones at about 1610,1520 and $1400 \mathrm{~cm}^{-1}$. After thermal decomposition, the resulting $\mathrm{Ln}_{2} \mathrm{O}_{2} \mathrm{SO}_{4}$ exhibited characteristic bands of $\mathrm{SO}_{4}{ }^{2-}$ ion coordinated to $\mathrm{Ln}^{3+}$ ion at 1210, 1130, 997, 664 and $619 \mathrm{~cm}^{-1}$, with an indication of low site symmetry in the oxysulfate. ${ }^{39}$ In contrast, the spectra of materials prepared by using Brij ${ }^{\circledR} 35$ exhibited a strong peak at $550 \mathrm{~cm}^{-1}$, typical for cubic-type $\mathrm{Ln}_{2} \mathrm{O}_{3}$ NPs. ${ }^{40}$

Energy dispersive X-ray spectroscopy (EDS) was further applied to determine the compositions of various Ln-based NPs. Fig. 3 reports the profiles for $\mathrm{Ho}_{2} \mathrm{O}_{2} \mathrm{SO}_{4}$ and $\mathrm{Ho}_{2} \mathrm{O}_{3} \mathrm{NPs}$, while the data corresponding to the Gd-analogues are given in the ESI (Fig. S5). It is clear that the obtained NPs are composed of $\mathrm{Ln}_{2} \mathrm{O}_{2} \mathrm{SO}_{4}$ and $\mathrm{Ln}_{2} \mathrm{O}_{3}$ when SDS and $\mathrm{Brij}{ }^{\circledR} 35$ were used, respectively. The solids obtained after thermal decomposition consisted of fairly uniform spherical particles, as determined by TEM images (Fig. 4 and S1 $\$$ ).

As mentioned above, with this technique it was also possible to observe how the use of octadecane as a co-stabilizing agent in miniemulsions affects the final size of the particles: under the same reaction conditions (Table 1, entries 2 and 3) the addition of octadecane ( $10 \mathrm{wt} \%$ with respect to Ln-acetylacetonate) led to 
a)
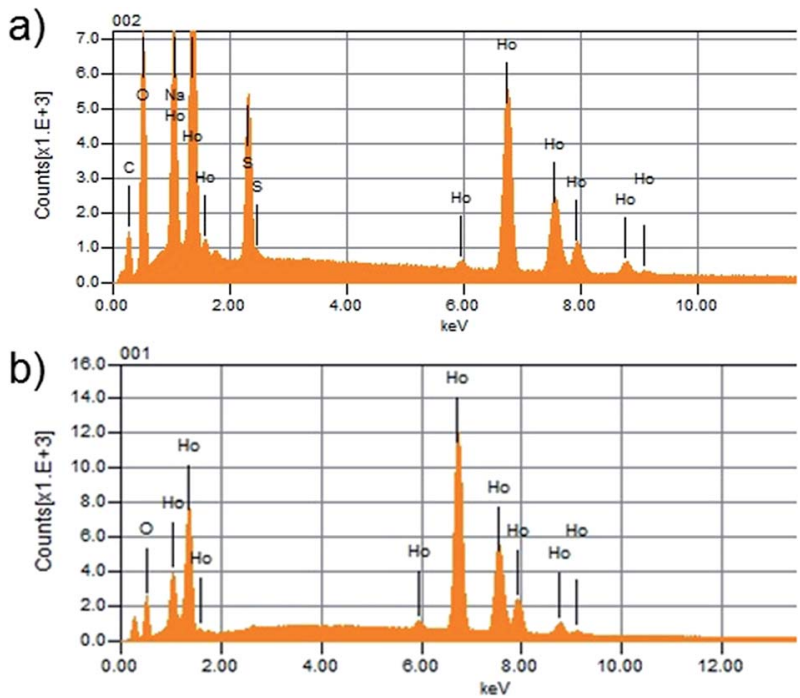

Fig. 3 EDS spectrum of (a) $\mathrm{Ho}_{2} \mathrm{O}_{2} \mathrm{SO}_{4}$ and (b) $\mathrm{Ho}_{2} \mathrm{O}_{3}$ NPs obtained after calcination.
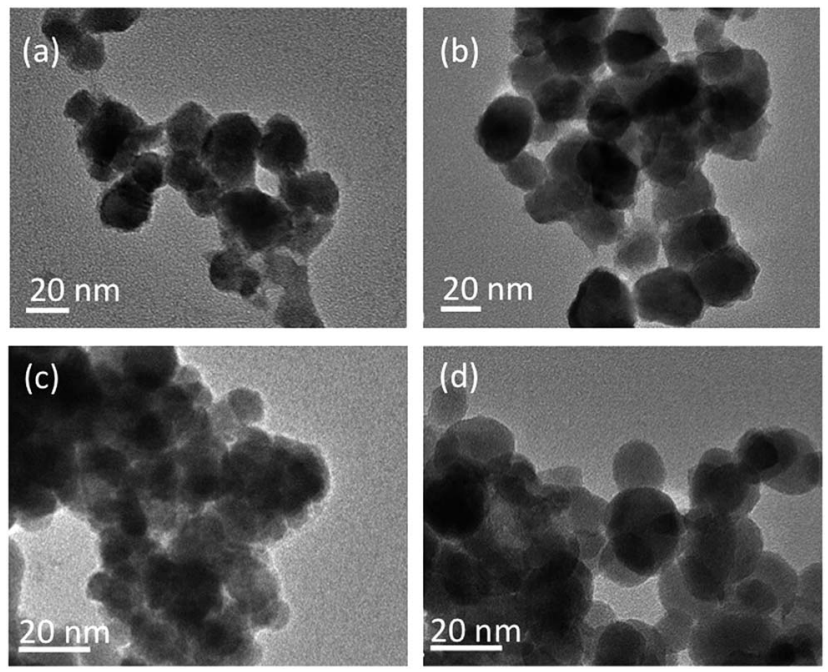

Fig. 4 TEM images of solid $\mathrm{Ho}_{2} \mathrm{O}_{2} \mathrm{SO}_{4}$ NPs prepared using SDS in the continuous phase: (a) and (b) correspond to entries 2 and 3 in Table 1 with 10 and 0 wt\% of octadecane in the dispersed phase, respectively; (c) and (d) correspond to entry 5 and 6 with 0 and 12.5 wt\% of ethanol added in the continuous phase, respectively.

particles (Fig. 4a) with a diameter $(18 \mathrm{~nm})$ smaller than that (24 nm) obtained in its absence (Fig. 4b). This effect is consistent with the reported claim that increasing the osmotic pressure leads to a decrease in the particles size. ${ }^{30}$ However, one of the advantages of the method discussed herein is that a hydrophobic co-reagent is not decisive in the preparation of nanodroplets.

As described above, changing the solvent of the dispersed phase from $\mathrm{CHCl}_{3}$ to DCM (Table 1, entries 3 and 5) resulted in Ho-loaded nanodroplets with a significantly reduced diameter (from 45 to $26 \mathrm{~nm}$ ). This is confirmed by the TEM images of the corresponding final $\mathrm{Ho}_{2} \mathrm{O}_{2} \mathrm{SO}_{4}$ particles (Fig. $4 \mathrm{~b}$ and c) with diameters 24 and $8 \mathrm{~nm}$, respectively. This further highlights the importance of the interfacial activity on the formation of the nanodroplets and, consequently, of the solid particles. The increase in size of the nanodroplets prepared with the addition of ethanol (Table 1, entry 6) is reflected in the TEM images of the corresponding final NPs (Fig. 4d), for which an average diameter of $8 \mathrm{~nm}$ was measured. Upon replacement of SDS with Brij® 35 as surfactant in the miniemulsion, the TEM images of $\mathrm{Ho}_{2} \mathrm{O}_{3}$ and $\mathrm{Gd}_{2} \mathrm{O}_{3}$ obtained upon calcination showed spherical particles with a diameter of 12 and $7 \mathrm{~nm}$, respectively (Fig. S6 Although the hydrodynamic diameters of the corresponding nanodroplets were by far larger (109 and $98 \mathrm{~nm}$, respectively) due to the long polymer chain of Brij ${ }^{\circledR} 35$ (Table 1, entries 9 and 10 , and Fig. S7 $\$$ ), the solid $\mathrm{Ln}_{2} \mathrm{O}_{3}$ particles showed the expected small sizes.

\section{Relaxivity and MRI studies of $\operatorname{Ln}_{2} \mathrm{O}_{2} \mathrm{SO}_{4}$ and $\operatorname{Ln}_{2} \mathrm{O}_{3} \mathrm{NPs}$}

As an example of their applicability, the Ln-NPs prepared as described above were evaluated in terms of their performance as magnetic resonance imaging contrast agents. Because of its seven unpaired $4 \mathrm{f}$-electrons $\mathrm{Gd}$ is the most paramagnetic stable metal ion, and therefore $\mathrm{Gd}^{3+}$-complexes are nowadays the most common longitudinal or $T_{1}$ CAs in medical MRI. ${ }^{11,42}$ On the other hand, Ho (together with dysprosium) is the most efficient transversal or $T_{2}$ CA for its highest magnetic moment. ${ }^{43}$ In view of their possible application as MRI CAs, the final Ho- or Gdbased NPs were evaluated for transverse $\left(r_{2}\right)$ and longitudinal $\left(r_{1}\right)$ proton relaxivities. The water proton relaxation rates $\left(R_{n}=\right.$ $1 / T_{n}, n=1$ or 2 ) of four samples of each lanthanide were measured at $25^{\circ} \mathrm{C}$ and $7 \mathrm{~T}$, and then plotted against the related concentration of paramagnetic $\mathrm{Ln}^{3+}$ ion in order to attain the corresponding relaxivity value as the slope of the obtained straight line (Fig. 5a). For $\mathrm{Gd}_{2} \mathrm{O}_{2} \mathrm{SO}_{4}(12 \mathrm{~nm})$ and $\mathrm{Gd}_{2} \mathrm{O}_{3}(7 \mathrm{~nm})$ particles $r_{1}$ is 1.0 and $3.1 \mathrm{mM}^{-1} \mathrm{~s}^{-1}$, respectively and is expected to be more impressive at the clinically used magnetic fields (1.5$3 \mathrm{~T}$ ), according to the typical ${ }^{1} \mathrm{H}$ nuclear magnetic relaxation dispersion profiles of solid NPs. ${ }^{20,42}$ The effect of particle size on the MRI contrast enhancement is demonstrated by the acquisition of $T_{1}$ - and $T_{2}$-weighted images of phantoms containing various concentrations of the particles at $25{ }^{\circ} \mathrm{C}$ and $7 \mathrm{~T}$. The brightness of $T_{1}$-weighted images acquired with $\mathrm{Gd}_{2} \mathrm{O}_{3}$ or $\mathrm{Gd}_{2} \mathrm{O}_{2} \mathrm{SO}_{4}$ particles of $7 \mathrm{~nm}$ increases with increasing concentrations between 0.1 and $0.3 \mathrm{mM}$ (Fig. 5b). This effect is in agreement with the obtained $r_{2} / r_{1}$ ratio of 10 , which is known to be favorable for $T_{1}$ contrast. $^{6}$ Increasing the particle size to 12 $\mathrm{nm}$ has a clear negative (dark) effect on the $T_{1}$-weighted intensity, due to higher $r_{2} / r_{1}$ ratio (up to 36 , Table 2) and a consequent dominance of $T_{2}$ on the intensity (Fig. 5b).

The $r_{2}$ values obtained for $\mathrm{Ho}_{2} \mathrm{O}_{3}(12 \mathrm{~nm})$ and $\mathrm{Ho}_{2} \mathrm{O}_{2} \mathrm{SO}_{4}$ $(18 \mathrm{~nm})$ are 31.1 and $43.9 \mathrm{mM}^{-1} \mathrm{~s}^{-1}$, respectively. The difference in diameter between the two systems must be taken into account, due to the strong linear dependence of $r_{2}$ on the particle size. ${ }^{44}$ Based on the low $r_{1}$ values, and consequently, high $r_{2} / r_{1}$ ratio, these particles are suitable for $T_{2}$-weighted imaging, as demonstrated in Fig. 5c. 
(a)

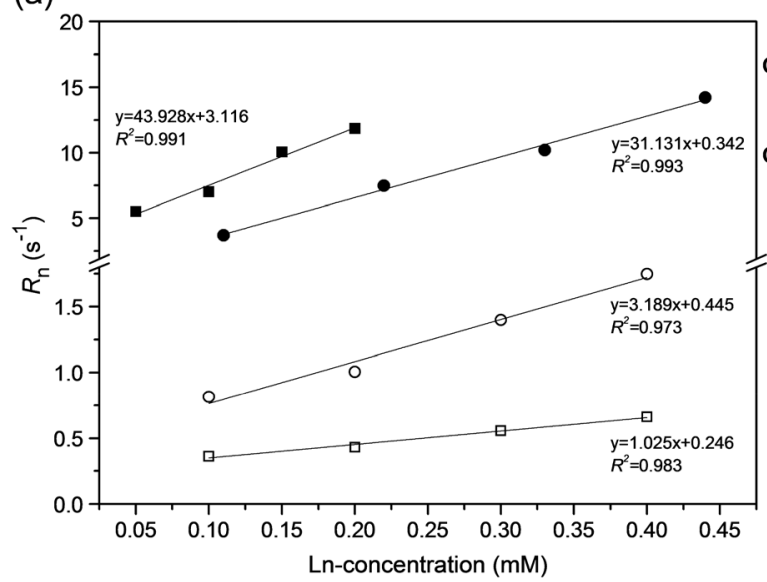

(b) $T_{1}$

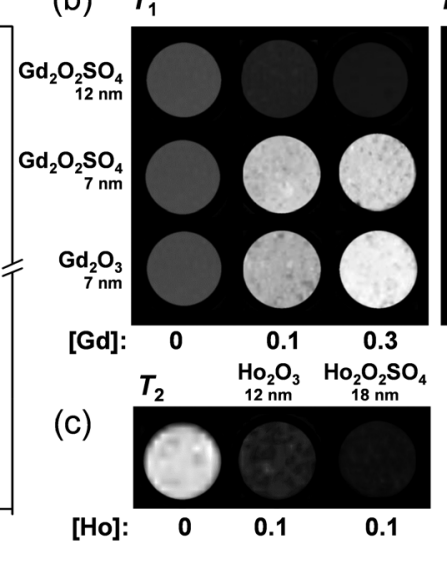

$T_{2}$

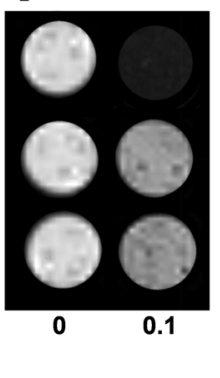

Fig. 5 MR relaxation rates and MR images of Gd-and Ho-based NPs dispersed in $0.5 \%$ solution of xanthan: (a) transversal (Ho, solid symbols) and longitudinal ( $\mathrm{Gd}$, open symbols) relaxation rates of oxysulfates (squares) and oxides (circles) NPs ( $7 \mathrm{~T}$ and $25^{\circ} \mathrm{C}$ ), (b) MR phantoms containing 0.1 and $0.3 \mathrm{mM} \mathrm{Gd}_{2} \mathrm{O}_{3}$ and $\mathrm{Gd}_{2} \mathrm{O}_{2} \mathrm{SO}_{4} \mathrm{NPs}\left(7 \mathrm{~T}\right.$ and $25^{\circ} \mathrm{C}$ ), left: $T_{1}$-weighted spin-echo $\mathrm{MR}$ images, $\mathrm{TE}=10.6 \mathrm{~ms}$ and $\mathrm{TR}=250 \mathrm{~ms}$; right: $T_{2}$-weighted $M R$ images, $T E=90 \mathrm{~ms}$ and $\mathrm{TR}=3 \mathrm{~s}$, (c) $T_{2}$-weighted images of xanthan phantoms containing $0.1 \mathrm{mM} \mathrm{Ho}_{2} \mathrm{O}_{3}$ and $\mathrm{HO}_{2} \mathrm{O}_{2} \mathrm{SO}_{4}$.

Table 2 Longitudinal and transversal relaxivities of Gd- and Ho-NPs as function of their size at $7 \mathrm{~T}$ and $25^{\circ} \mathrm{C}$

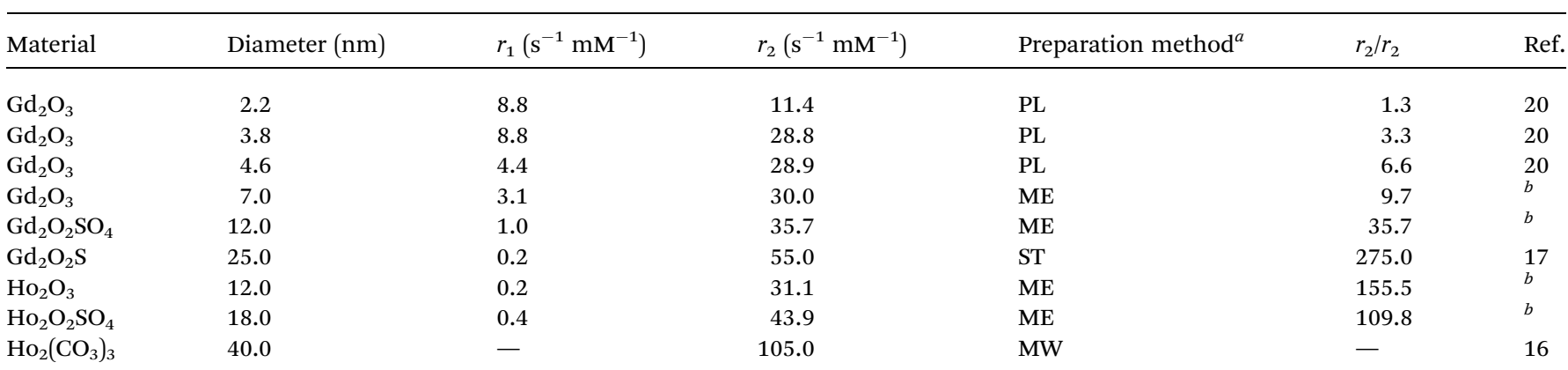

${ }^{a} \mathrm{PL}=$ polyol; $\mathrm{ME}=$ miniemulsion; $\mathrm{ST}=$ solvothermal; $\mathrm{MW}=$ microwave. ${ }^{b}$ This work.

Besides the size and chemical composition, several experimental parameters, such as temperature, $\mathrm{pH}$, strength of the applied magnetic field etc. determine the $r_{1}$ and $r_{2}$ of NPs. Therefore, the relaxivities of even similar types of NPs reported in the literature often cannot be compared directly. Taking this into account, in Table 2 a small selection of literature data is compiled to demonstrate the consistency of the relaxivities of Gd- and Ho-NPs obtained by different preparation methods, and measured under the same conditions $\left(7 \mathrm{~T}, 25^{\circ} \mathrm{C}\right)$. The data clearly show a decrease of $r_{1}$ for Gd-NPs upon increasing their particle size as the consequence of the decrease in the surfaceto-volume ratio for oxides as well as for oxysulfates and oxysulfides.

Ho-containing NPs show a strong size-dependence of $r_{2}$. The chemical composition of NPs seems to be of minor importance, as the values for oxide, oxysulfate and carbonate follow the same linear increase of $r_{2}$ upon increase in the size. Finally, the relaxivities of Gd- and Ho-NPs obtained from the miniemulsion method fit perfectly in the $r_{n} v s$. diameter trend and are in agreement with those previously reported for analogous Lncontaining NPs. ${ }^{41}$

\section{Conclusions}

We have demonstrated a facile miniemulsion technique and subsequent thermal decomposition that can be advantageously applied for the preparation of Ln-containing NPs. Such methodology is particularly useful for the preparation of NPs in the size range of 5 to $40 \mathrm{~nm}$ as it is far less time-consuming, more reproducible and results in a higher productivity than the polyol strategies suitable for ultrasmall NPs. Therefore, the present miniemulsion method is a valid and convenient alternative strategy with attractive advantages for the synthesis of Ln-NPs.

The formation of nanodroplets under emulsion conditions is highly influenced by the selection of the surfactant and the nature of the dispersed and continuous phases. In the present study, the interfacial activity and the type of surfactant revealed to be the key parameters determining not only the size of the nanodroplets and hence the final solid particles, 
but also their chemical composition. In particular, depending on the surfactant used, the main products are either lanthanide oxysulfates or oxides. By adjusting these parameters, spherical NPs with a defined diameter can be readily obtained through further thermal decomposition. Both types of particles exhibited the relaxivities that are in accordance with the values reported in the literature. The $r_{2}$ relaxivities measured on smaller Ho-NPs $(<20 \mathrm{~nm})$ confirm the linear sizedependence reported previously for larger Ho-NPs $(>40$ $\mathrm{nm}) .{ }^{16}$ The MR images indicate a good $T_{2}$-weighted contrast, and hence, suitability of these NPs prepared by the miniemulsion method as $T_{2}$ CAs after a proper surface functionalization. On the contrary, the $r_{1}$ relaxivities of Gd-containing NPs decrease with the particle size, and as the result of $T_{2^{-}}$ effect becoming dominant, the brightness of the $T_{1}$-weighted MR images acquired with bigger Gd-NPs $(>7 \mathrm{~nm})$ is lower. These observations demonstrate the importance of sizecontrol for the applications of Ln-based nanoparticles as MRI CAs.

Considering the similarity of chemical properties of the f-elements, the present technique can be predictably expanded for the preparation of NPs of the whole series of lanthanides to be exploited in a variety of fields such as catalysis (oxysulfates for oxygen storage/release), ${ }^{2}$ optics (oxides with luminescence properties), ${ }^{1}$ and diagnostics (paramagnetic nanoparticles). ${ }^{43}$

\section{Acknowledgements}

This research was performed in the framework of the EU COST Action TD1004, "Theranostics Imaging and Therapy: an Action to Develop Novel Nanosized Systems for Imaging-Guided Drug Delivery" and supported by China Scholarship Council (W. Z.) and the Netherlands Organization for Scientific Research (K. D. and J. M., NWO Veni grant-722.012.009). The authors thank Ms. Wan Gengping (Hainan University, China) for TEM and Mr Ben Norder (Delft University of Technology) for the XRD measurements.

\section{Notes and references}

1 S. V. Eliseeva and J.-C. G. Bunzli, Chem. Soc. Rev., 2010, 39, 189-227.

2 M. Machida, K. Kawamura, K. Ito and K. Ikeue, Chem. Mater., 2005, 17, 1487-1492.

3 S. Comby, E. M. Surender, O. Kotova, L. K. Truman, J. K. Molloy and T. Gunnlaugsson, Inorg. Chem., 2013, 53, 1867-1879.

4 Y. Liu and N. Zhang, Biomaterials, 2012, 33, 5363-5375.

5 K. Nicolay, G. Strijkers and H. Grüll, in The Chemistry of Contrast Agents in Medical Magnetic Resonance Imaging, John Wiley \& Sons, Ltd, 2013, pp. 449-487.

6 J. A. Peters and K. Djanashvili, Eur. J. Inorg. Chem., 2012, 2012, 1961-1974.

7 M. A. Bruckman, X. Yu and N. F. Steinmetz, Nanotechnology, 2013, 24, 20.
8 W. Lin, Y. Hou, Y. Lu, A. I. Abdelrahman, P. Cao, G. Zhao, L. Tong, J. Qian, V. Baranov, M. Nitz and M. A. Winnik, Langmuir, 2014, 30, 3142-3153.

9 T. Kihara, Y. Zhang, Y. Hu, Q. Mao, Y. Tang and J. Miyake, J. Biosci. Bioeng., 2011, 111, 725-730.

10 S.-D. Li and L. Huang, Mol. Pharm., 2008, 5, 496-504.

11 F. Lu, S.-H. Wu, Y. Hung and C.-Y. Mou, Small, 2009, 5, 14081413.

12 C. He, Y. Hu, L. Yin, C. Tang and C. Yin, Biomaterials, 2010, 31, 3657-3666.

13 G. Sonavane, K. Tomoda and K. Makino, Colloids Surf., B, 2008, 66, 274-280.

14 N. Lu, X. Song and J. Zhang, Mater. Lett., 2009, 63, 10891092.

15 J. A. Nelson, L. H. Bennett and M. J. Wagner, J. Am. Chem. Soc., 2002, 124, 2979-2983.

16 F. Mayer, J. A. Peters and K. Djanashvili, Chem.-Eur. J., 2012, 18, 8004-8007.

17 S. A. Osseni, S. Lechevallier, M. Verelst, P. Perriat, J. DexpertGhys, D. Neumeyer, R. Garcia, F. Mayer, K. Djanashvili, J. A. Peters, E. Magdeleine, H. Gros-Dagnac, P. Celsis and R. Mauricot, Nanoscale, 2014, 6, 555-564.

18 C. Truillet, F. Lux, J. Moreau, M. Four, L. Sancey, S. Chevreux, G. Boeuf, P. Perriat, C. Frochot, R. Antoine, P. Dugourd, C. Portefaix, C. Hoeffel, M. Barberi-Heyob, C. Terryn, L. van Gulick, G. Lemercier and O. Tillement, Dalton Trans., 2013, 12410-12420.

19 B. Zhang, H. Jin, Y. Li, B. Chen, S. Liu and D. Shi, J. Mater. Chem., 2012, 22, 14494-14501.

20 J.-L. Bridot, A.-C. Faure, S. Laurent, C. Rivière, C. Billotey, B. Hiba, M. Janier, V. Josserand, J.-L. Coll, L. Vander Elst, R. Muller, S. Roux, P. Perriat and O. Tillement, J. Am. Chem. Soc., 2007, 129, 5076-5084.

21 N. Abrikossova, C. Skoglund, M. Ahrén, T. Bengtsson and K. Uvdal, Nanotechnology, 2012, 23, 275101.

22 G. Chen, H. Qiu, P. N. Prasad and X. Chen, Chem. Rev., 2014, 114, 5161-5214.

$23 \mathrm{~J}$. G. Assouline and S. K. Sweeney, WO Pat., WO2014035620A1, 2014.

24 N. Luo, X. Tian, C. Yang, J. Xiao, W. Hu, D. Chen and L. Li, Phys. Chem. Chem. Phys., 2013, 15, 12235-12240.

25 K. Landfester, in Colloid Chemistry II, ed. M. Antonietti, Springer, Berlin, Heidelberg, 2003, vol. 227, ch. 4, pp. 75-123.

26 T. G. Mason, J. N. Wilking, K. Meleson, C. B. Chang and S. M. Graves, J. Phys.: Condens. Matter, 2006, 18, R635.

27 S. B. Barrios, J. F. Petry, C. K. Weiss, C. L. Petzhold and K. Landfester, J. Appl. Polym. Sci., 2014, 131, 40569.

28 E. Schreiber, U. Ziener, A. Manzke, A. Plettl, P. Ziemann and K. Landfester, Chem. Mater., 2009, 21, 1750-1760.

29 Y. Yang, E. S. Daniels and A. Klein, J. Appl. Polym. Sci., 2015, 132, 41933-41940.

30 K. Landfester, N. Bechthold, F. Tiarks and M. Antonietti, Macromolecules, 1999, 32, 5222-5228.

31 D. M. Corsi, C. Platas-Iglesias, H. v. Bekkum and J. A. Peters, Magn. Reson. Chem., 2001, 39, 723-726.

32 M. Antonietti and K. Landfester, Prog. Polym. Sci., 2002, 27, 689-757. 
33 L. L. Hecht, C. Wagner, K. Landfester and H. P. Schuchmann, Langmuir, 2011, 27, 2279-2285.

34 A. H. Demond and A. S. Lindner, Environ. Sci. Technol., 1993, 27, 2318-2331.

35 J. Zhang, Z. Chen, Z. Wang, W. Zhang and N. Ming, Mater. Lett., 2003, 57, 4466-4470.

36 A. K. Chesters, Chem. Eng. Res. Des., 1991, 69, 259-270.

37 M. Machida, K. Kawamura, T. Kawano, D. Zhang and K. Ikeue, J. Mater. Chem., 2006, 16, 3084-3090.

38 D. Zhang, F. Yoshioka, K. Ikeue and M. Machida, Chem. Mater., 2008, 20, 6697-6703.

39 M. Machida, T. Kawano, M. Eto, D. Zhang and K. Ikeue, Chem. Mater., 2007, 19, 954-960.
40 N. T. McDevitt and W. L. Baun, Spectrochim. Acta, 1964, 20, 799-808.

41 T. J. Kim, K. S. Chae, Y. Chang and G. H. Lee, Curr. Top. Med. Chem., 2013, 13, 422-433.

42 É. Tóth, L. Helm and A. Merbach, in The Chemistry of Contrast Agents in Medical Magnetic Resonance Imaging, John Wiley \& Sons, Ltd, 2013, pp. 25-81.

43 M. Norek and J. A. Peters, Prog. Nucl. Magn. Reson. Spectrosc., 2011, 59, 64-82.

44 M. Norek, E. Kampert, U. Zeitler and J. A. Peters, J. Am. Chem. Soc., 2008, 130, 5335-5340. 